\title{
Technical Design of Flexible Thin-Film Solar Heating Clothes with Switchable Output Power
}

\author{
Yu Xiao Zhao ${ }^{1, a}$, Ya Li Li ${ }^{1}$, \& Li Min Shi ${ }^{1}$ \\ ${ }^{1}$ The School of Fashion Art and Engineering, Beijing Institute of Fashion Technology, No. 2 A Yinghua Road, Chaoyang District, Beijing, \\ 100029, China
}

\begin{abstract}
This research focuses on the research and development of thermal clothes through technical design, by adopting unique removable electronic equipment and applying carbon fiber material to thermal clothes against cold, so as to meet the requirements of active heating and passive warmth retention. Firstly, the specification of power supply system was determined in accordance with the requirements of power system, and the specification of charging system was determined according to the specification of power system. Then circuit system was designed and tested. Fianlly, the electronic device was configured on the clothes appropriately, so that it should be conforms to ergonomic principles, convenient and fast.
\end{abstract}

Keywords: Heating clothes, flexible thin-film solar cells, carbon fiber, wearable technology.

\section{Introduction}

With the social and economic development, people have increasingly high requirements for energy. Solar energy, as a new energy resource, has huge development potential. Solar heating clothes which can be used to replace traditional thermal clothes are a new type of self-heating clothes. On one hand, the clothes can eliminate the limitation of charging with power supply during outdoor activities. On the other hand, the application of the new material of carbon fiber makes the thermal clothing develop from passive warmth retention to active warmth retention. Thus, the clothing is lighter and more beautiful. At the same time, the unique electronic equipment and removable design facilitate the cleaning of clothes, to maximize the potential safety hazard, which is an innovative attempt to warm clothing.

\section{Functional Requirement for Heating Clothes}

Based on the heat exchange form between human body and external environment, firstly, it was confirmed that the applicable circumstance temperature for the clothes is $0^{\circ} \mathrm{C}$. Secondly, it was determined that the thermal insulation of the clothes during heat exchange between human body and environment to reduce heat exchange to the greatest extent and maintain the balance between heat production and heat release of human body at a comfortable state. Thus, the passive thermal functional requirement for flexible thin-film solar heating clothes is reducing convection heat loss and increasing the resistance of internal and external thermal conduction of clothes. This requires the clothes having good warmth retention property for human body heat and good wind protective effect for cold air to reduce cold air invasion and cause air cooling effect. Then, it is required to supplement the inadequate heat by autonomic regulation of human body and the heat loss through various heat exchanges between human body and external environment. And electric heating units are required for active heating to reach thermal comfort. The functional requirements for specific active heating are as follows:

(1) The internal temperature of electric heating clothes should be maintained within the human body comfort temperature and can be manually adjusted in accordance with external environment and person's needs.

(2) Electric heating unit adopt portable rechargeable batteries. The batteries can be charged with the charger for direct charging indoor and it is inconvenient to charge outdoor. Thus, flexible solar cells can be used for charging.

\section{Specification Setting and Electronic Device Selecting}

\section{Specification Setting}

Firstly, the specification of power supply system was determined in accordance with the requirements of power system, namely load. Then the specification of charging system, namely solar cells was determined according to the specification of power system, namely lithium battery.

The specification of the load - heating unit is determined as $9 \mathrm{~W}$ according to the applicable temperature of $0^{\circ} \mathrm{C}$. The voltage of lithium battery is selected as lower than $12 \mathrm{~V}$ according to the safety voltage which the body can bear (the voltage of single lithium battery is $3.7 \mathrm{~V}$, the voltage of lower than $12 \mathrm{~V}$ includes $3.7 \mathrm{~V}, 3.7 \times 2=7.4 \mathrm{~V}$ and $3.7 \times 3=11.1 \mathrm{~V}$ ). Due to the heating quantity that human body can feel, the load current should reach up to $1 \mathrm{~A}$ at least. In accordance with the formula 1 , the selected battery specification is $7.4 \mathrm{~V}$ at last. Then the specification of solar cells is determined in accordance with the charging principle of lithium battery.

\footnotetext{
${ }^{a}$ Corresponding author: yuxiao.z@163.com
} 
$\mathrm{I}=\mathrm{P} / \mathrm{U}$

(1)

In the formula: P-Power (W);

$$
\text { U-Supply voltage (V); }
$$

I- Current (A).

Lithium battery is the battery which has high requirements for charging voltage. Over charge or discharge will cause irreparable damage to battery and battery failure [1]. Explosion can be caused due to serious overcharge. Polymer lithium battery (PLB) is a new generation of lithium battery. Compared with the original Liquified lithium-ion battery (LIB), PLB is featured with thinness, arbitrary area and arbitrary shape. In addition, there is no liquid leakage, combustion explosion and other safety problems. At the same time, the specific energy of PLB is more than $50 \%$ of the current ordinary lithium battery. The capacity, charge and discharge characteristics, safety, operating temperature range, cycle life and environmental performance are improved greatly [2]. So the PLB is adopted in this research.

At present, the electrochemical window of the electrolyte of the anode and cathode material adopted by the PLB on the market is basically over $4.5 \mathrm{~V}$. That is to say, when charging voltage of battery reaches $4.5 \mathrm{~V}$, the battery is in a stale state. However, if the charging voltage of battery is too low (lower than $4.15 \mathrm{~V}$ ), the charge level of battery will be affected greatly. If the charging voltage is controlled at $4.13 \mathrm{~V}$, the charged electric quantity is about $60 \sim 80 \%$ of the battery capacity, which will greatly affect the battery performance [3]. To sum up, the charging voltage for single lithium battery shall be controlled within $4.2 \sim$ $4.5 \mathrm{~V}$. The lithium battery charging voltage of $7.4 \mathrm{~V}$ obtained by two lithium batteries connected in series should be within $8.4 \sim 9.0 \mathrm{~V}$. That is to say, the charging voltage of solar cells shall be within the range mentioned above.

\section{Electronic Device Selecting}

\section{Flexible Thin-film Solar Cells}

The dimension of each solar cell is $190 \mathrm{~mm}$ in length, $50 \mathrm{~mm}$ in width and $1 \mathrm{~mm}$ in thickness. And the single cell weights $20 \mathrm{~g}$. The optimum operating voltage is $1.5 \mathrm{~V}$ and the optimum operating current is $300 \mathrm{~mA}$. The open circuit voltage is $1.5 \mathrm{~V}$ and short-circuit current is $380 \mathrm{~mA}$, as shown in Fig.1.

Five solar cells can be selected for charging. Single measured charging voltage is $1.9 \mathrm{~V}$ and the output voltage of the whole piece of solar panel composed by five solar cells is $9.5 \mathrm{~V}$. And the charging current is $250 \mathrm{~mA}$. As the output current of solar cells changes with illumination intensity, a diode should be connected in series between flexible solar cell and lithium battery. The diode shall be positive onset in reverse blocking state [4] to avoid the inverse current due to voltage and current dip, which is lower than the voltage of lithium battery, after sunlight is blocked or charging direction changes sharply. In addition, the diode has step-down function. After a diode is connected in series, the measured charging voltage is $9.0 \mathrm{~V}$ and the charging current is $220 \mathrm{~mA}$, which basically meet the requirements of the charging voltage and current.

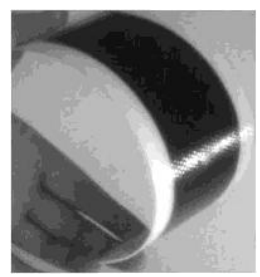

Fig. 1 Flexible

thin-film amorphous

silicon solar cell

\section{Lithium Battery}

Two specifications of the same voltage and different capacity are used. The battery capacity of the preferred outdoor solar charging equipment is $1300 \mathrm{mAh}$ and the charging time is within $5 \sim 6$ hours. In addition, indoor charger for direct charging can also be used and the charging time is 1.3 hours. The battery capacity of the preferred indoor charger for direct charging is $2200 \mathrm{mAh}$ and the charging time is 2.2 hours (outdoor solar charging equipment can also be used but the charging time is relatively long for about 10 hours). The two batteries are provided with protective circuit with overcharge and over-discharge protection functions. The over-charged protection voltage is $8.4 \pm 0.05 \mathrm{~V}$ and the over-discharged protection voltage is $6.0 \pm 0.05 \mathrm{~V}$. That is to say, if the voltage is more than $8.4 \pm 0.05 \mathrm{~V}$ and lower than $6.0 \pm 0.05 \mathrm{~V}$ after charging, the circuit will cut off automatically. And no-load removal will be delayed or charging will automatically release.

\section{Lithium Battery Charger for Direct Charge}

Input specification is $\mathrm{U}=\mathrm{AC} 100 \sim 240 \mathrm{~V}, \mathrm{P}=47 \sim$ $63 \mathrm{~Hz}$ and $\mathrm{I}=0.5 \mathrm{~A}$, output specification is $\mathrm{U}=\mathrm{DC} 8.4 \mathrm{~V}$ and $\mathrm{I}=1 \mathrm{~A}$. Charging mode is constant current first and then constant voltage. For charging, the charging light is red. For a full charge and on load, the charging light is green. This is because charger is equipped with guard plate. When battery voltage is about $8.4 \mathrm{~V}$ and charging current is less than about $50 \mathrm{~mA}$, the protection circuit will cut off charging current.

\section{Carbon Fiber Wire}

The carbon fiber wire produced by Toray is adopted and the specification is $12 \mathrm{k}$. Electrical resistivity $\mathrm{R} 1=32 \Omega / \mathrm{m}$, as shown in Fig. 2 .

First, the resistance and length of resistance wire, namely carbon fiber wire were obtained in accordance with the formula 2.

$$
\mathrm{RT}=\mathrm{U}^{2} / \mathrm{P}
$$

In the formula: P__ Power (W); 


$$
\begin{array}{lll}
\mathrm{U}=3.7 \times 2=7.4 \mathrm{~V} ; & \mathrm{U}-\text { Supply voltage } & (\mathrm{V}), \\
\mathrm{RT}=7.4^{2} / 9=6.08 \Omega . & (\Omega),
\end{array}
$$

Because the specification of the purchased carbon fiber resistance wire is $12 \mathrm{k}$, that is to say, there are 12000 carbon fibers for each bunch of carbon fiber and the parallel connection with $\mathrm{N}=8$ is adopted. The resistivity of the carbon fiber resistance wire per centimeter is $\mathrm{R} 2=\mathrm{R} 1 / \mathrm{N}=0.32 / 8=0.04 \Omega$; the length of carbon fiber wire meets the requirement $\mathrm{L}=\mathrm{R}_{\mathrm{T}} / \mathrm{R} 2=6.08 / 0.04=150 \mathrm{~cm}$.

\section{Temperature Controller}

The single-chip micro-controller provided by Shenzhen Kanghualin Industry Company is adopted, as shown in Fig. 3, $2 \mathrm{~cm}$ at the widest point and less than $5 \mathrm{~g}$ in weight. The resin encapsulated type is featured with accurate control, low-voltage operation, less energy consumption and beautiful appearance. The controller can control output power through controlling the output current of lithium battery, so as to control the temperature of heating unit.

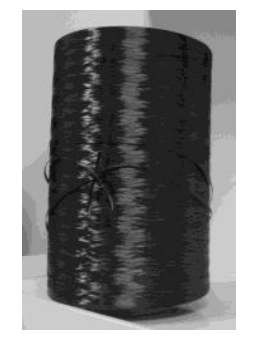

Fig. 2 Carbon fiber wire produced by Toray

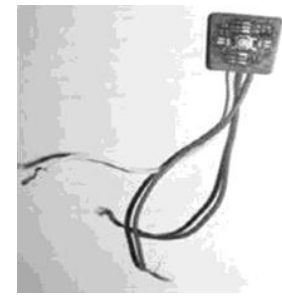

Fig. 3 Temperature controller

\section{Work Principle of Circuit}

\section{Charging Circuit of Solar Cells} 4.

The charging circuit of solar cells is as shown in Fig.

\section{Solar Cell Charging Process}

Flexible solar cell can generate current with sunlight and charge lithium battery by diode. After pressing the switch, when the lithium battery voltage is $8.4 \mathrm{~V}$ displayed on the digital display module, the charging is complete (the charge cut-off voltage of $3.7 \mathrm{~V}$ single lithium battery is $4.2 \mathrm{~V}$ and the charge cut-off voltage of two lithium batteries is $8.4 \mathrm{~V}$ ). As the charging current of solar cells is small, which can be regarded as constant flow source low current charging, at this time, the voltage of lithium battery increases gradually? In general, when the voltage reaches up to $8.4 \mathrm{~V}$, the charging is completed.

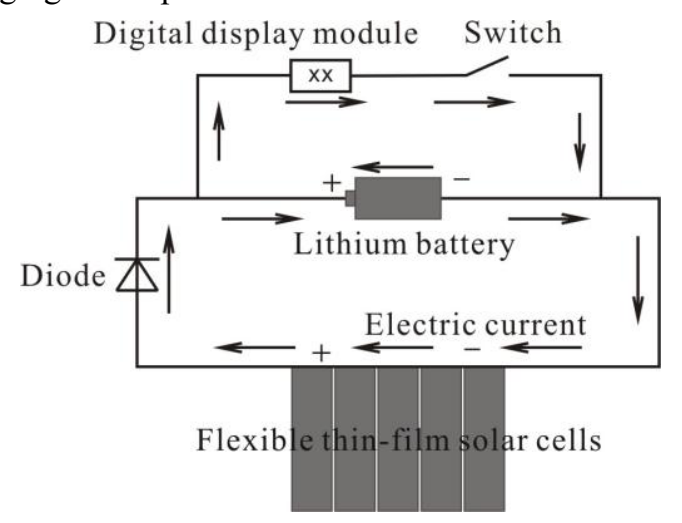

Fig. 4 Solar cell charging circuit diagram

\section{Solar Cell Charging Test}

When the lithium battery power is used until automatic over-discharge protection is started and the voltage decreases to $6 \mathrm{~V}$, the electric quantity is 0 at this time. After charging the lithium battery in the sun, the measured $1300 \mathrm{mAh}$ lithium battery charging curve is shown as in Fig. 5. From the figure, it can be seen that when the voltage is between $6 \mathrm{~V}$ and $7.5 \mathrm{~V}$, the charging rate is fast. When the voltage is greater than $7.5 \mathrm{~V}$, the voltage increases slowly. When the voltage reaches $8.1 \mathrm{~V}$, the voltage is basically stable for 6 hours. At this time, the lithium battery is fully charged. Then the lithium battery can be removed for use.

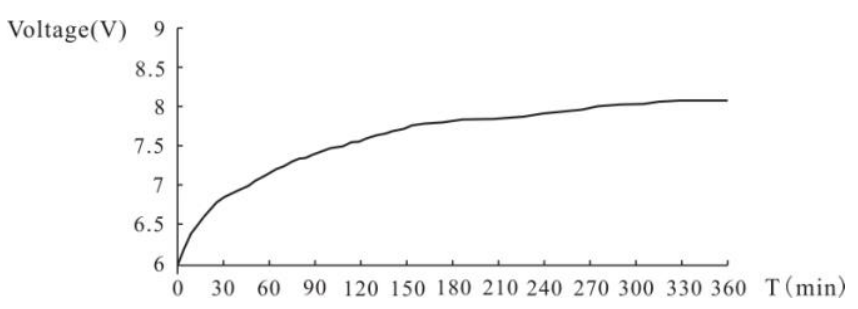

Fig. 5 Lithium battery charging voltage time profile

\section{Temperature-Regulated Active Heating Circuit of Electric Heating Unit}

Temperature-regulated active heating circuit of electric heating unit is as shown in Fig. 6.

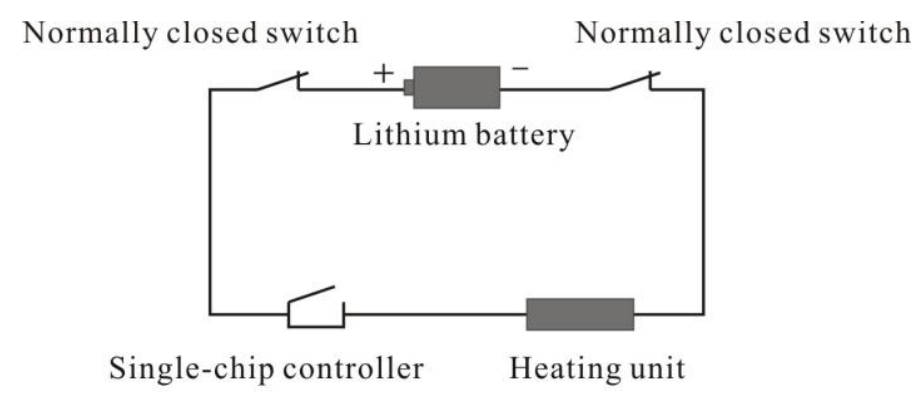

Fig. 6 Temperature-regulated active heating circuit diagram of electric heating unit 


\section{Working Process of Electric Heating Unit Active Heating}

Long press the controller button for three seconds. And LED displays red flashing light. At this time, carbon fiber wire is at preheating condition. Then short press the button. The LED displays red freeze-frame. At this time, the power output is about $98 \%$. Then press the button again. The LED displays white freeze-frame. At this time, the power output is about $75 \%$. Press the button again. The LED displays blue freeze-frame. And the power output is about $60 \%$. Then long press the button for 3 seconds, LDE indicator light is off without power output. Two $50^{\circ} \mathrm{C}$ temperature switches are connected in parallel inside heater band. One switch is located at the chest position and the other switch is installed at the lumbar spine. When the circuit is normal working state, the bimetallic strip on switch is in free state, and the connector is closed. When the temperature reaches $50^{\circ} \mathrm{C}$, the circuit can be cut off by any switch, with dual temperature protection, so as to avoid hazard due to excess temperature.

\section{Lithium Battery Discharge Test Results}

When $2300 \mathrm{mAh}$ lithium battery is fully charged, for red gear output, the measured service time is 160 minutes. For white gear output, the measured service time is 220 minutes. For blue gear output, the measured service time of lithium battery is 280 minutes. When $1300 \mathrm{mAh}$ lithium battery is fully charged, for red gear output, the measured service time is 1 hour. For white gear output, the measured service time is 80 minutes. For blue gear output, the measured service time is 100 minutes.

\section{Overall Wiring Diagram inside Clothing}

The design principle of the integration of the electronic device for flexible thin-film temperature-adjustable heating clothes and clothes is to configure the electronic device on the clothes appropriately on condition that the electronic device can be operated normally. The wire between devices should be reduced as far as possible. In addition, for electronic device operation, it shall be conforms to ergonomic principles, convenient and fast. For integration of electronic device and clothes, zipper, adhesive button and other design shall be adopted as far as possible. The used electronic equipment shall be easy to remove. The overall wiring diagram inside clothes is as shown in Fig. 7.

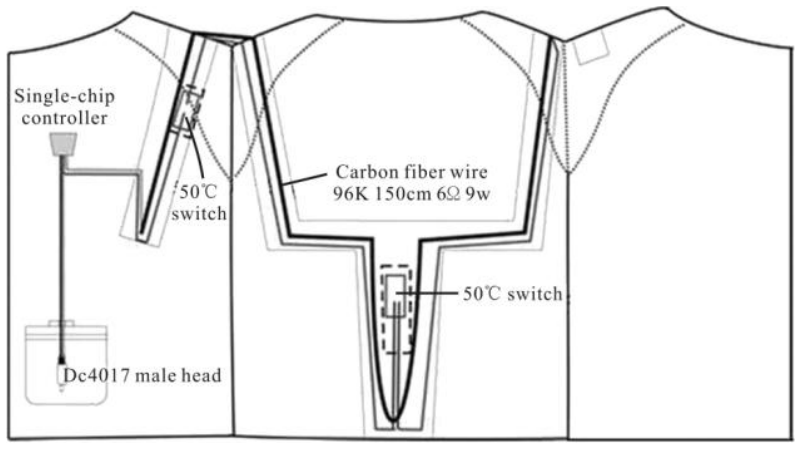

Fig. 7 Overall wiring diagram inside clothing

\section{Conclusion}

Based on the principle of reducing heat exchange as far as possible, this research determines the functional requirement of warm clothes which performs active heating on the basis of strengthening passive heat preservation to make up heat production and offset heat release in accordance with the heat exchange form between human body and external environment in cold environment, so as to determine the electric heating form of active heating.

The active heating of warm clothes is achieved as follows: in order to charge lithium battery through solar cells, with temperature-adjustable and heating electric heater bands, first, set the specification of electronic device and determine the specification of load, power supply unit and charging equipment successively. In accordance with the set specification of electronic device, select the mature electronic product on the market, design and test the whole circuit. The results show that the whole circuit reaches the requirements of technical design required for this research.

\section{References}

[1] C.H. Li, N. Wang, Analysis of Performance of Lithium-ion Battery, Inner Mongolia Science Technology \& Economy. 2012(12) 71-74.

[2] B.Z. Qian, Development Situation and Prospects of Polymer Lithium-ion Battery, World Plastics. 2010(12) 44-47.

[3] Description of Polymer Lithium Battery Charging Voltage on http://www.hqew.com/tech/fangan

[4] X.C. Deng, C.Y. Lai, Role Recognization of Diode in the Circuit, Journal of Jinggangshan Normal College. 2002(S2)88-89. 